\title{
Sur la logique des stoïciens
}

\section{Jan Lukasiewicz}

Traducteur : Anna Zielinska

\section{CpenEdition}

\section{Journals}

Édition électronique

URL : http://journals.openedition.org/philosant/1485

DOI : 10.4000/philosant. 1485

ISSN : 2648-2789

Éditeur

Éditions Vrin

\section{Édition imprimée}

Date de publication : 1 novembre 2011

Pagination : 9

ISBN : 978-2-7574-0356-3

ISSN : $1634-4561$

\section{Référence électronique}

Jan Lukasiewicz, «Sur la logique des stoïciens », Philosophie antique [En ligne], 11 | 2011, mis en ligne le 01 novembre 2018, consulté le 15 septembre 2020. URL : http://journals.openedition.org/philosant/ 1485

\section{(c) (i) $\odot$}

La revue Philosophie antique est mise à disposition selon les termes de la Licence Creative Commons Attribution - Pas d'Utilisation Commerciale - Pas de Modification 4.0 International. 


\section{SUR LA LOGIQUE DES STOÏCIENS}

La logique des stoïciens a été déjà étudiée par Prantl, Zeller et Brochard. Aucun d'entre eux ne l'a comprise, car aucun n'avait de formation suffisante en logique. Il est vrai que cela ne peut même pas leur être reproché, car, après tout, où pouvaient-ils l'apprendre ? Leurs jugements sur la logique stoïcienne n'ont aucune valeur.

Ce n'est qu'aujourd'hui que nous savons, grâce à la logique mathématique, que la logique des stoïciens est un système entièrement différent de la syllogistique d'Aristote. La logique stoïcienne constitue en effet le correspondant de la « théorie de la déduction » contemporaine, et ces mots sont utilisés ici dans le sens de Russell et Whitehead dans leurs Principia Mathematica. Il s'agit donc d'une théorie qui n'inclut que les variables de propositions, alors que la syllogistique d'Aristote ne contient que des variables de noms. Aujourd'hui, nous savons également que la logique stoïcienne, en tant que théorie de la variable propositionnelle, est le système logique fondamental dont la signification est incomparablement plus grande et plus générale que celle de la logique aristotélicienne. Un système de logique aristotélicienne correctement construit doit s'appuyer déjà sur les thèses de la théorie de la déduction, autrement dit : sur la logique stoïcienne. Déjà les stoïciens eux-mêmes ont été, semble-t-il, conscients de cet état de choses; il se peut que l'on puisse dire de même de certains péripatéticiens, comme par exemple - selon le témoignage de Galien - Boèce.

De ce point de vue il faut que l'histoire de la logique stoïcienne soit écrite à nouveau et les jugements qui ont été formulés à son propos doivent être révisés. En étudiant les sources, je me suis rendu compte du fait que l'ouvrage d'Arnim, Stoicorum veterum fragmenta, pour précieux qu'il soit, n'est pas suffisant pour bien connaitre la logique stoïcienne. Il faut aller jusqu'aux auteurs eux-mêmes. Sextus Empiricus semble être le plus important parmi eux, et il comprend parfaitement la logique des stoïciens (ses textes exigent cependant $-c f$. par exemple $A d v$. Math. VIII 230-233 - une reconstruction presque évidente). Ensuite, nous avons les commentateurs d'Aristote, en particulier Alexandre; enfin Galien. Une attention particulière doit être accordée à l'Introduction à la dialectique de Galien, découverte au XIX ${ }^{\mathrm{e}}$ siècle par Minas. Peut-être la dernière place dans cette liste d'auteurs pourrait-elle être occupée par Diogène Laërce. Un exemple intéressant de la logique stoïcienne, négligé par Prantl et Arnim, se trouve dans le Contre Celse d'Origène.

M. Heryng et M. Łukasiewicz ont participé à la discussion.

Traduit du polonais par Anna Zielinska 